\title{
A baculovirus-mediated strategy for full-length plant virus coat protein expression and purification
}

Daniel Mendes Pereira Ardisson-Araújo ${ }^{1}$, Juliana Ribeiro Rocha', Márcio Hedil Oliveira da Costa', Anamélia Lorenzetti Bocca ${ }^{1}$, André Nepomuceno Dusi ${ }^{2}$, Renato de Oliveira Resende ${ }^{1}$ and Bergmann Morais Ribeiro ${ }^{* *}$

\begin{abstract}
Background: Garlic production is severely affected by virus infection, causing a decrease in productivity and quality. There are no virus-free cultivars and garlic-infecting viruses are difficult to purify, which make specific antibody production very laborious. Since high quality antisera against plant viruses are important tools for serological detection, we have developed a method to express and purify full-length plant virus coat proteins using baculovirus expression system and insects as bioreactors.

Results: In this work, we have fused the full-length coat protein (сp) gene from the Garlic Mite-borne Filamentous Virus (GarMbFV) to the 3'-end of the Polyhedrin (polh) gene of the baculovirus Autographa californica multiple nucleopolyhedrovirus (AcMNPV). The recombinant baculovirus was amplified in insect cell culture and the virus was used to infect Spodoptera frugiperda larvae. Thus, the recombinant fused protein was easily purified from insect cadavers using sucrose gradient centrifugation and analyzed by Western Blotting. Interestingly, amorphous crystals were produced in the cytoplasm of cells infected with the recombinant virus containing the chimeric-protein gene but not in cells infected with the wild type and recombinant virus containing the hexa histidine tagged Polh. Moreover, the chimeric protein was used to immunize rats and generate antibodies against the target protein. The antiserum produced was able to detect plants infected with GarMbFV, which had been initially confirmed by RT-PCR.

Conclusions: The expression of a plant virus full-length coat protein fused to the baculovirus Polyhedrin in recombinant baculovirus-infected insects was shown to produce high amounts of the recombinant protein which was easily purified and efficiently used to generate specific antibodies. Therefore, this strategy can potentially be used for the development of plant virus diagnostic kits for those viruses that are difficult to purify, are present in low titers or are present in mix infection in their plant hosts.
\end{abstract}

Keywords: Baculovirus expression system, Polyhedrin, Garlic virus coat protein, Virus-indexing diagnostic kit

\footnotetext{
* Correspondence: bergmann@unb.br

${ }^{1}$ Department of Cell Biology, Laboratory of Electron Microscopy, Institute of Biological Sciences, University of Brasília, Brasília, DF, Brazil

Full list of author information is available at the end of the article
} 


\section{Background}

For the establishment of a successful large-scale agricultural production, the use of healthy and pathogen-free plants is an essential measure. Garlic, for instance, has no virus-free cultivars, which represents a serious problem due to economic losses and the difficulties of controlling disease. Considering all agronomic parameters important for garlic production, bulb growth is the most severely affected by virus infections, causing a decrease in productivity and quality, with a reduction of up to $88 \%$ of the weight [1-3]. In fact, the introduction of the first virus-free cultivars produced in Brazil by thermotherapy and stem-tip culture has resulted in improved yields [4].

However, for the efficient production of tissue culture virus-free plants, some bottlenecks must be overcome. One of them is the detection of virus infections in garlic plants. Current detection is based on serological methods, using specific antiserum, symptomatology, transmission tests in different host plants, and sequence data of the coat protein gene $[5,6]$. In situations when a high number of samples need to be tested, the use of molecular diagnosis techniques, such as RT-PCR, is not an easy task, due to the requirement of expensive and fragile materials (e.g. enzymes, dNTPs, termocycler). Therefore, serological methods are recommended for large scale evaluations, however, high quality antisera are not available for all relevant viruses $[7,8]$. The dotEnzyme-Linked Immunosorbent Assay (dot-ELISA) is a serological, less expensive and more practical alternative method that could be used to detect plant virus infections, despite of requiring the production of specific antibodies.

Many plant viruses of agricultural interest, including the garlic-infecting viruses, are difficult to purify from the host because they accumulate in low titers and are often present in mixed infections, which make specific antibody production very laborious [9-11].

One way of circumventing these difficulties is to express the virus coat protein in prokaryotic or eukaryotic cell systems for further antisera production. The expression of a soluble coat protein from a garlic virus in bacteria (Resende RO, personal communication) and insect cells [12] for production of antiserum for the recombinant protein was previously carried out by our research group but neither system worked. We were unable to produce high titer antibody due to problems in protein purification, which makes it unsuitable for the largescale species-specific diagnosis of the tested garlic viruses. Despite baculovirus being a potent tool to express different proteins, the purification step is usually a challenge for further applications. To solve this problem, one could attempt to tag the recombinant protein with a carrier peptide or protein to facilitate the antigen purification.
Interestingly, the orally infective baculovirus virions are surrounded by protein crystal matrix composed mainly of a single protein, the Polyhedrin, which is highly expressed in the late stages of infection [13]. Polyhedrin has been used as a carrier protein to facilitate antigen purification [14-18]. This strategy for purification of antigen has been patented (see http:/otl.sinica. edu.tw/en/index.php?t=9\&group_id=19\&article_id=477). The system has advantages when compared to existing technologies, it is both easy and cheap and achieves a purity of over $95 \%$ without the need for tags or expensive column purification steps. In this work we have expressed the coat protein of the Allexivirus GarMbFV (Garlic mite-borne filamentous virus) in caterpillars as bioreactors using a Polyhedrin-based expression vector in order to generate polyclonal antibodies for a potential development of a large-scale dot-ELISA-mediated virusindexing diagnostic kit.

\section{Results}

\section{Fusion vectors and recombinant virus construction}

In order to express a chimeric protein containing the GarMbFV coat protein fused to the AcMNPV polhgene, a shuttle vector, pFB1-polh-6xHis with a modified polh gene was constructed (Figure 1). This modified ORF shows a unique $\mathrm{NcoI}$ restriction site for fusion in frame of any gene at the 3 '-end and also six histidine codons for recombinant protein immunoblotting identification (Figure 1A-I and B). The GarMbFV coat protein gene was amplified (Figure 1A-II and C) and inserted into the modified polh gene to generate the plasmid pFB1-polhGarMbFV-cp-6xHis (Figure 1A-III). The modified vector presented a new ORF containing the fusion protein Polh-GarMbFV-CP-6xHis (Figure 1D). Both derived vectors were used to construct the recombinant viruses, vAc-polh-6xhis and vAc-polh-GarMbFV-cp-6xhis by the Bac-to-bac system (Invitrogen). The recombinant viruses were amplified in insect cells and confirmed by PCR analysis (not shown). Furthermore, a donor vector was constructed for homologous recombination to generate an engineered virus expressing the non-fused GarMbFV$c p$. This soluble protein was expressed under the control of a late and a very late promoter in tandem (Wang et al., 1991) present in the recombinant vector pSynGarMbFV-cp.

\section{Recombinant protein analysis}

Synthesis of recombinant proteins was analyzed by immunoblotting. Virus-infected Tn5B extracts were separated by $12 \%$ SDS-PAGE (not shown) and the proteins transferred to a nitrocellulose membrane. The proteins were detected using anti-hexa-histidine antibody (anti-6xHis) and anti-Polh antiserum (anti-Polh) (Figure 2). An immunoreactive band of $29.9 \mathrm{kDa}$ was detected in 

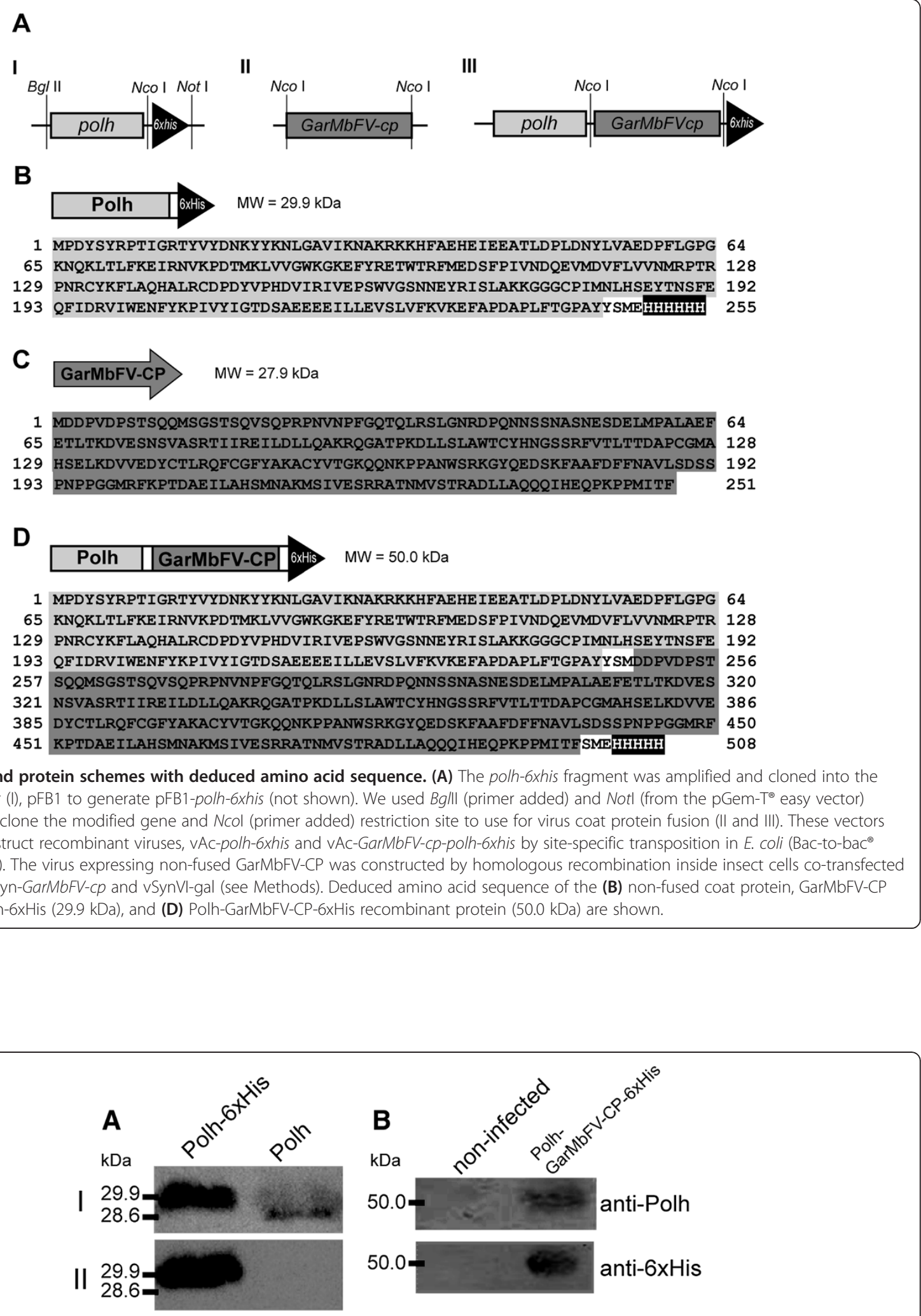

Figure 2 Expression analysis of wild type Polyhedrin and recombinant proteins. AcMNPV-, vAc-polh-6xhis- and vAc-polh-GarMbFV-cp-6xhis-infected Tn5B extracts were separated by $12 \%$ SDS-PAGE (not shown) and the proteins transferred to nitrocellulose membranes. The membranes were then treated with specific antibodies anti-Polh (I - upper panels in $\mathbf{A}$ and $\mathbf{B}$ ) and anti-6xHis ( $\|$ - lower panels in $\mathbf{A}$ and $\mathbf{B}$ ). The anti-Polh detected the wild type Polyhedrin as well as the recombinant protein fused to Polyhedrin. On the other hand, the anti-6xHis detected only the recombinant proteins. 
extracts of vAc-polh-6xHis-infected cells (72 h p.i.) when using anti-Polh antiserum (Figure 2A, I) and anti-6xHis (Figure 2A, II). No bands were detected in non-infected cell extracts (not shown). Further, when extracts from AcMNPV-infected cells were tested with the same antibodies, just one band reacted with the anti-Polh, showing a smaller mass of $28.6 \mathrm{kDa}$ (Figure 2A) as expected. Additionally, extracts containing the chimeric protein Polh-GarMbFVcp$6 \mathrm{xHis}$ were probed with anti-Polh and anti-6xHis showing a $50 \mathrm{kDa}$ immunoreactive band, thus revealing correct recombinant protein fusion and expression. No band was detected in mock-infected cell extracts (Figure 2B).

\section{Light microscopy analysis of cells infected with recombinant viruses}

vAc-polh-6xhis and vAc-polh-GarMbFV-cp-6xhis-infected Tn5B cells (72 h p.i.) were analyzed by light microscopy. Occlusion bodies resembling wild type polyhedra were detected in the nucleus of vAc-polh-6xhis-infected cells (black arrows, Figure 3A). When cells were infected with vAc-polh-GarMbFV-cp-6xhis, it was possible to see irregular shaped crystals mainly in the cells' cytoplasm (white arrows, Figure 3B).

\section{Analysis of purified recombinant crystals}

Purified occlusion bodies from wild type and recombinant virus-infected $S$. frugiperda larva were analyzed by scanning electron microscopy. All occlusion bodies formed a distinct band on the sucrose gradient (Figure 4A). AcMNPV occlusion bodies showed a regular cubic shape as expected (Figure 4B-I), on the other hand, the vAc-polh-6xhis showed mainly triangular shaped occlusion bodies (Figure 4B-II) and the vAc-polhGarMbFV-cp-6xhis showed putative occlusion bodies of amorphous shape (Figure 4B-III).

\section{Antiserum production and identification of GarMbFV-infected garlic plants}

The purified fusion protein Polh-GarMbFV-CP was solubilized and used to immunize rats. The antiserum was tested in extracts derived from infected insect cells and garlic plants with visible virus infection symptoms (mosaic) by SDS-PAGE/immunoblotting and Dot-ELISA technique, respectively. Virus-infected Tn5B extracts were separated by $12 \%$ SDS-PAGE (not shown) and transferred to a nitrocellulose membrane. Immunoreactive bands of 29.9 and $50.0 \mathrm{kDa}$ were detected in extracts of vAc-polh6xhis- and vAc-polh-GarMbFV-cp-6xhis-infected cells (72 h p.i.) using anti-Polh-GarMbFV-CP-6xHis antiserum (Figure 5A, lane 1). Furthermore, the antiserum produced was tested against vSyn-GarMbFV-cp- and mock-infected extract cells. Two immunoreactive bands were found in the first extract, one of $29.9 \mathrm{kDa}$, the molecular weight of the Polyhedrin and another one of $27.9 \mathrm{kDa}$, the GarMbFV-CP weight, as expected. The specificity of the antiserum produced against insect cell was checked and there was no detection of any protein in mock-infected cell extracts (Figure 5A, lane 2).

For dot-ELISA, the purified fusion protein (A), both GarMbFV-infected $(\mathrm{C}+)$ and uninfected $(\mathrm{C}-)$ garlic leaf extracts were used as controls (Figure 6 square $\mathrm{A}, \mathrm{C}+$, and $\mathrm{C}$-). Garlic leaf extracts from nine different plants showing symptons of virus infection reacted with the produced antiserum (Figure 6, numbers 1 to 3 and 5 to 9). On the other hand, the extract number 4 , even presenting symptoms, did not react with the antiserum (Figure 6). RT-PCR was carried out to corroborate the dot-ELISA results. The same positive and negative results were observed by the serological technique (not shown).

\section{Discussion}

Brazil produces less garlic (Allium sativum) than it consumes, even with a local production reaching 140,000 t

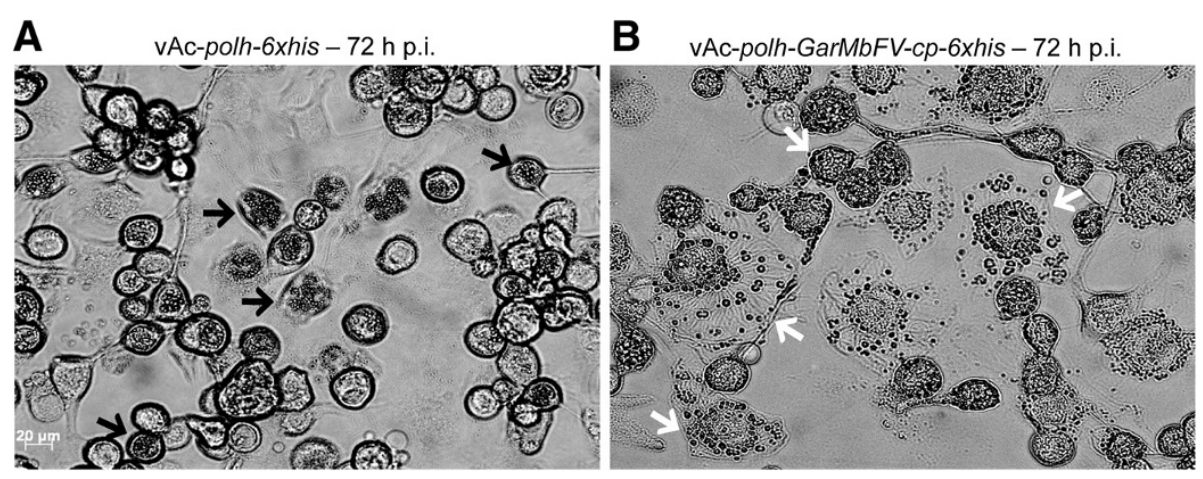

Figure 3 Structural analysis of both vAc-polh-6xhis- and vAc-polh-GarMbFV-cp-6xhis-infected Tn5B cells at 72 h p.i. (A) vAc-polh-6xhisinfected cells showing the presence of numerous occlusion bodies inside the cell nucleus (black arrows). (B) vAc-polh-GarMbFV-cp-6xhis-infected Tn5B cells showing the occlusion bodies derived from the recombinant fused protein mainly in the cytoplasm of the cells (white arrows). Scale bar $=20 \mu \mathrm{m}$ 


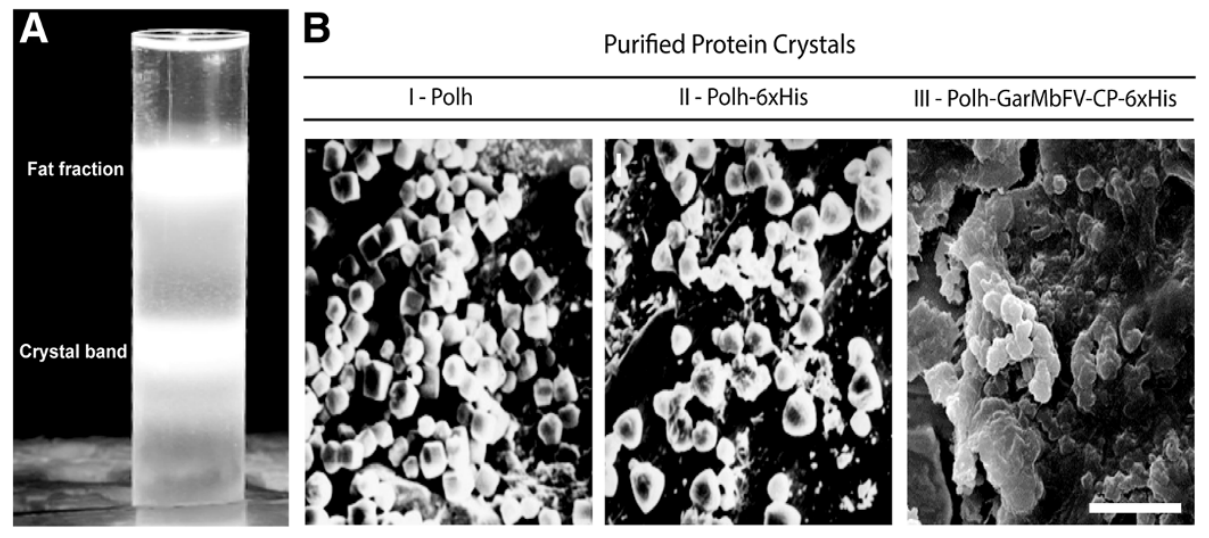

Figure 4 Purification and ultrastructural analysis of occlusion bodies derived from wild type and recombinant viruses infected insects. AcMNPV polyhedra (Polh) and Polh-6xHis and Polh-GarMbFV-CP-6xHis crystals from infected S. frugiperda cadavers were purified by centrifugation through a sucrose gradient. (A) A centrifuge tube after centrifugation of vAc-polh-GarMbFV-cp-6xHis-infected insect extracts showing a lower band containing the putative crystals. The upper band shows the fat fraction from the insect cadavers. (B) The crystals were collected from the gradient and prepared for scanning electron microscopy: (I) Occlusion bodies from wild type AcMNPV infected insect cadavers; (II) Occlusion bodies from vAc-polh-6xhis-infected insect cadavers showing a triangular shaped crystal; and (III) Occlusion bodies-like from vAc-polh-GarMbFV-cp-6xhis-infected insect cadavers showing some crystals and undefined mass protein of Polh-GarMbFV-CP-6xHis (Scale bar $=5 \mu \mathrm{m})$.

in 2011 (Brazilian Institute of Geography and Statistics http://www.ibge.gov.br). Sixty percent of the total Brazilian fresh or chilled garlic imports are from China (Ministry of Development, Industry, and Foreign Trade - http:// www.desenvolvimento.gov.br), and there is no phytosanitary barriers to garlic import and other plants, making the introduction of infected plants with potentially new pathogens a constant threat $[19,20]$. Utilizing a garlic virus coat protein as a model, we proposed the use of caterpillars as bioreactors and Polyhedrin as a carrier protein to facilitate the large-scale purification of full-length recombinant proteins of significant agricultural importance.

Polyhedrin-based amorphous crystals carrying the complete coat protein (cp) from GarMbFV in virus-infected insect cells and larvae were successfully produced. The incorporation of GarMbFV-CP into the polyhedra-like amorphous crystal depended on the structure of the new chimeric protein generated, which prevents the natural form, nuclear occlusion body formation and therefore, no virion incorporation into the occlusion body. Roh et al. [16] hypothesized that interactions between chimeric Polyhedrins can occur, but these protein masses are not as compact as the wildtype polyhedra. Ji et al. [21] resolved the structure of the AcMNPV polyhedra revealing a highly symmetrical covalently cross-braced robust lattice with flexible adaptors for virion occlusion. The Polyhedrin subunit may be broken down into three parts: $\mathrm{N}$-terminal head, a $\beta$-barrel body, and $\mathrm{C}$-terminal tail [21]. Here, we fused the complete GarMbFVcp gene in the Polyhedrin C-terminal tail without a proteolytic site. This tail is able to form a hook,
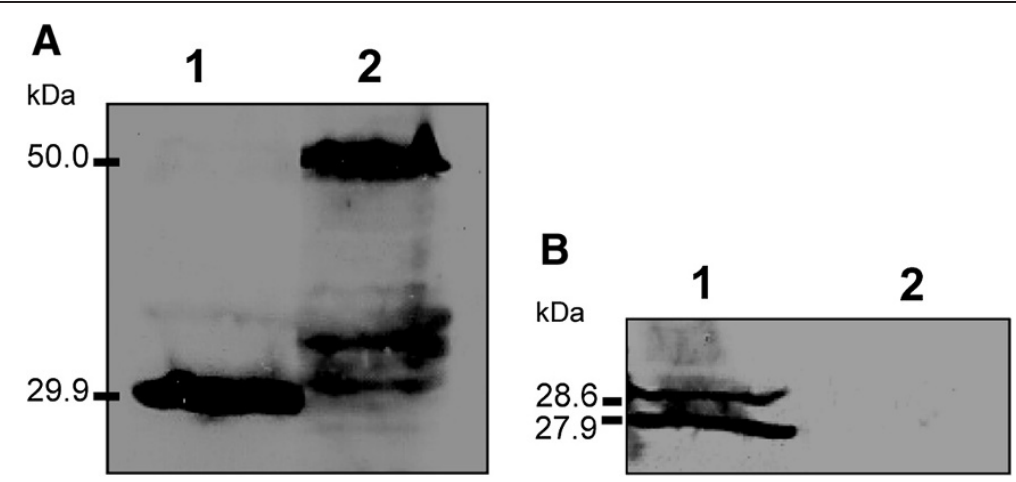

Figure 5 Immunoblot against infected- and non-infected-insect cell extracts using anti-Polh-GarMbFV-CP-6xHis. vAc-polh-6xhis-, vAc-polh-GarMbFV-cp-6xhis-, and vSyn-GarMbFV-cp-infected Tn5B extracts were separated by 12\% SDS-PAGE (not shown) and transferred to nitrocellulose membrane. The membranes were treated with the antiserum anti-Polh-GarMbFV-CP-6xHis crystals. (A) Polh-6xHis (lane 1) and chimeric protein Polh-GarMbFV-CP-6xHis (lane 2). (B) Soluble GarMbFV-CP and Polh from vSyn-GarMbFV-cp- (lane 1) and non-infected cells extract (lane 2). Lower bands in lane 2 of figure A are most probably degradation products of the Polh-GarMbFV-CP-6xHis protein. 


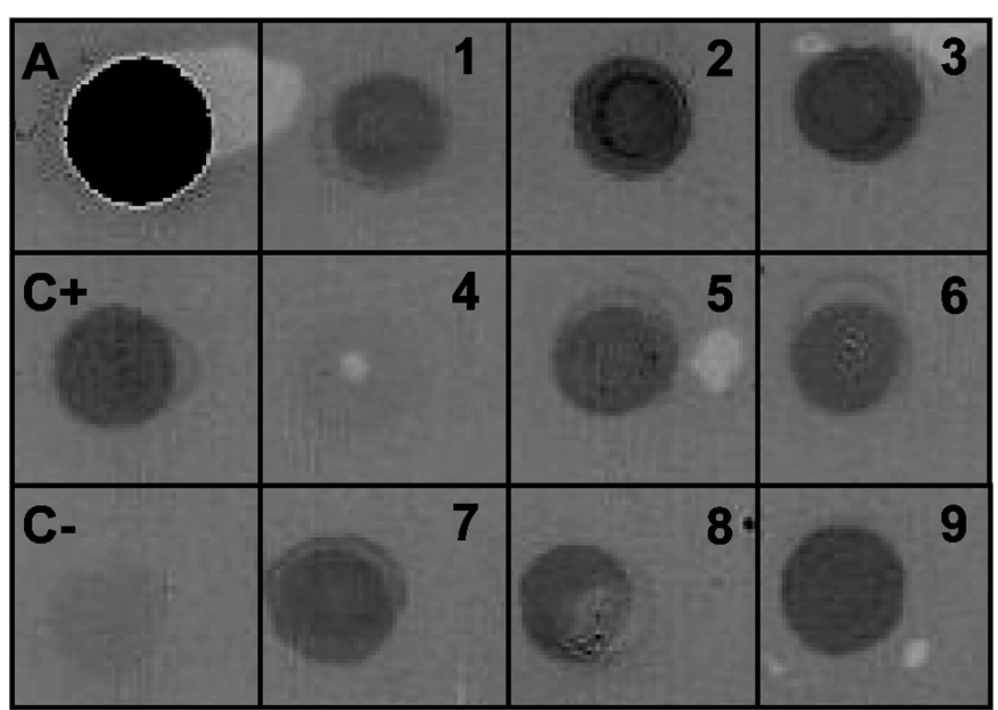

Figure 6 Dot-ELISA of garlic leaf extracts. A shows the antigen (baculovirus-expressed GarMbFV-CP) used to obtain the antiserum, (C+) shows a positive control derived from a GarMbFV-infected leaf extract confirmed by RT-PCR (not shown), in (C-) a virus-free garlic leaf extract as negative control. Nine extracts (1 to 9) from different plants showing virus infection symptoms were denaturated with modified Laemmili's buffer,

manually dotted, and tested with the antiserum obtained in this work. Only sample 4 did not react with the antiserum produced.

jutting outwards which interacts with another Polyhedrin to form the crystal. Thus, the amorphous-shaped protein mass observed by scanning microscopy compared to the wild-type and the 6x-His-tagged Polyhedrin (Figure 4B), is probably due to both the size of the fused gene and the cterminal fusion with the Polyhedrin protein. This feature avoided the polyhedral matrix formation and the nuclear localization by the chimeric protein. Previous research has used, besides the polh gene fused with a gene of interest, a second polh gene copy $[14,17]$. Although the presence of a second copy of polh could improve the chimeric crystal formation and nuclear localization, we observed that the presence of only one fused Polyhedrin-copy was sufficient to form a crystal structure. This allows recombinant protein purification from insect cadavers and cells as previously observed in vitro [16]. The purification of the recombinant protein is carried out by using sucrose gradient centrifugation which is both easier and cheaper than column chromatography which is normally used for recombinant protein purification.

The expression of the full-length fusion protein produced a polyhedra-like crystal that presented altered occlusion body morphology and localization, but this alteration did not affect protein purification in our study. Purified crystals carrying the GarMbFVcp showed that the coat protein antigens elicited the production of antibodies in rats. The results indicated that immunization with a chimeric protein induced a significant serum antibody reaction against Polyhedrin and the coat protein. This demonstrated that both were immunogenic and that the baculovirus protein perhaps increases the immune response as previously observed [17,22] for another baculovirus carrier protein and the Polyhedrin. Similar methods have already been developed and employed to purify target proteins [16-18]; however, the novelty presented here is the expression of a full-length protein in fusion with the Polyhedrin and the use of complete cadavers of caterpillars as bioreactors.

Unlike what was observed by Alves-Junior et al. [12], the antiserum produced by this new approach using the Polyhedrin as a full-length protein carrier was able to detect infected plants in dot-ELISA assays and to distinguish infected from non-infected plants at a high antiserum dilution (1:1,000 from the crude antiserum) and this detection was confirmed by RT-PCR using specific GarMbFV-cp primers (data not shown).

A challenge for a virus-indexing diagnosis in the field is the fact that this particular garlic disease is caused by a viral complex [20]. In Brazil alone, three virus genera related to garlic mosaic symptoms [3] were found: Potyvirus [Onion yellow dwarf virus (OYDV) and Leek yellow stripe virus (LYSV)] [23], Carlavirus [Garlic common latent virus (GCLV) and Shallot latent virus (SLV)] [23,24], and Allexivirus, [Garlic miteborne filamentous virus (GarMbFV), Garlic virus $C$ (GarV-C) and Garlic virus $D$ (GarV-D)] $[8,25]$. Notably, a symptomatic plant was found to be negative for GarMbFV, in both dotELISA and RT-PCR tests, suggesting that the produced antiserum did not cross-react to other viruses in the complex, although more experiments are necessary to confirm this result. Moreover, indirect ELISA or sandwich ELISA kits based on our strategy can be also developed. 


\section{Conclusions}

The expression of a plant virus full-length coat protein gene fused to the baculovirus Polyhedrin in recombinant baculovirus-infected insects was shown to produce high amounts of the recombinant protein which was easily purified and efficiently used to generate specific antibodies. Therefore, this strategy could be used for the development of plant virus diagnostic kits of those viruses that are difficult to purify, are in low titers, or are present in mix infections in their plant hosts.

\section{Methods}

\section{Insect cells, viruses and insects}

Trichoplusia ni (cabbage looper) BTI-Tn5B1-4 (Tn5B) cells [26] were maintained in TC-100 medium (HIMEDIA) supplemented with $10 \%$ fetal bovine serum (Invitrogen), and an antibiotic-antimycotic mixture (Gibco) at $28^{\circ} \mathrm{C}$. Wild type Autrographa californica multiple nucleopolyhedrovirus (AcMNPV); vSynVI-gal [27] (an AcMNPV recombinant which contains the $\beta$-galactosidase (lac-Z) gene in place of the polh gene); recombinant viruses vSynGarMbFV-cp, vAc-polh-GarMbFV-cp-6xhis and, vAcpolh-6xhis constructed in this work have been propagated and their titers determined according to O'Reilly et al. [28]. Spodoptera frugiperda larvae, the fall armyworm, in early five-instar was provided by EMBRAPA/CENARGEN - Genetic Resources and Biotechnology (Brasília, Brazil), maintained at $25^{\circ} \mathrm{C}$, and fed on an artificial diet [29]. The infection was carried out by injection of $10 \mu \mathrm{l}$ of medium containing recombinant virus $\left(10^{6}\right.$ viruses in BV phenotype) into the hemocoel.

\section{Coat protein and polh amplification}

The GarMbFV coat protein (GarMbFVcp) [25] (Genbank accession number X98991) was amplified using the FGarMbFVcp $^{N}$ (CCA TGG ACG ACC CTG TTG ACC CAA GC) and R-GarMbFVcp ${ }^{\mathrm{N}}$ (CCA TGG AGA ACG TAA TCA TGG GAG G) oligonucleotides that modify the stop-codon and add $\mathrm{NcoI}$ restriction sites (in italics) flanking the gene for posterior fusion. The AcMNPV polh gene was modified by PCR in order to construct the fusion vector. Forward primer (Acpol-BglII F) adds a BglII restriction site (in italics) (CCG AGA TCT ATG CCA GAT TAT AGC TAT AGG CC) at the 5 -terminus and the reverse primer (Ac-pol/hisc NcoI R) removes the gene stop-codon and adds a NcoI restriction site (in italics), and six histidines codons (underlined sequence) at the 3'terminus (TTA GTG ATG ATG ATG ATG ATG TTC CAT GGA ATA ATA CGC GGG GCC GGT AAA CAG AGG TGC). The PCR program used for both reactions was: $94^{\circ} \mathrm{C} / 5 \mathrm{~min}, 35$ cycles of $94^{\circ} \mathrm{C} / \mathrm{s}, 50^{\circ} \mathrm{C} / 20 \mathrm{~s}$ and $72^{\circ} \mathrm{C} /$ $40 \mathrm{~s}$ and a final extension for $7 \mathrm{~min}$ at $72^{\circ} \mathrm{C}$. Reactions contained $10 \mathrm{ng}$ of DNA-sample, $300 \mu \mathrm{M}$ of dNTP mix (Fermentas), $0.4 \mu \mathrm{M}$ of each set of primers previously described, and the LongAmp enzyme (New England Biolabs). The modified fragments obtained (GarMbFV-cp and polh-6xHis) were analyzed by electrophoresis in $0.8 \%$ agarose gels [30], eluted using the GFX PCR DNA and Gel Band Purification kit (GE Healthcare), cloned into the pGem-T easy vector (Promega), and sequenced (Macrogen, Korea) to certify the modifications.

\section{Fusion vector and recombinant virus construction}

The polh-6xhis gene was removed from the cloning vector by BglII and NotI restriction digestion following the manufacturer's instructions (Promega) and analyzed by electrophoresis in a $0.8 \%$ agarose gel [30]. The DNA fragment was then purified using the GFX ${ }^{\text {su }}$ PCR DNA and Gel Band Purification Kit (GE Healthcare) and cloned into the commercial donor vector $\mathrm{pFastBac}^{\circ}$ (pFB1 - Invitrogen) previously digested with BamHI and NotI (Promega) restriction enzymes in order to generate the recombinant plasmid pFB1-polh-6xhis. The NcoI-flanked GarMbFV-cp gene, was removed from the pGem-T easy vector by NcoI restriction digestion, the fragment was analyzed by electrophoresis and purified from the gel as described above. The purified fragment was then introduced into the unique $\mathrm{NcoI}$ site present in the pFB1-polh-6xhis plasmid in order to construct the pFB1-polh-GarMbFV-cp-6xhis plasmid. Both vectors (pFB1-polh-6xhis and pFB1-polh-GarMbFV-cp-6xhis) were transformed into DH10-Bac cells (Invitrogen) by electroporation [30] and recombinant bacmids were selected following the manufacturer's instructions (Bac-to$\mathrm{Bac}^{\circ}$, Baculovirus expression systems, Invitrogen). DNA from the bacmids were purified and the presence of the recombinant gene was checked by PCR using specific oligonucleotides as described by the manufacturer's protocol (Invitrogen). One microgram of each recombinant bacmid was transfected into Tn5B cells $\left(10^{6}\right)$ using liposomes (Cellfectin ${ }^{\circ}$ ) according to manufacturer's instructions (Invitrogen). Since naked baculovirus DNA is infectious, the supernatant of 7 days post-transfection Tn5B cells containing the recombinant viruses were collected, tittered, and the virus amplified by infection of $1,5 \times 10^{7}$ cells with a MOI of 1 in $75 \mathrm{~cm}^{2}$ flasks (TPP) as described in O'Reilly et al. [28].

For the construction of a recombinant virus containing the coat protein gene, the previously described plasmid, pGem-GarMbFV-cp [25], was digested with EcoRI (Promega) and analyzed by electrophoresis in a $0.8 \%$ agarose gel [30]. The DNA fragment was purified as previously described and cloned into the unique EcoRI restriction site of the transfer vector pSynXIVVI + X3 [27], which enables insertion of the heterologous gene under the control of two strong promoters in tandem (pSyn and pXIV). The vector pSynXIVVI $+\mathrm{X} 3$ had been previously digested with EcoRI (Promega) and dephosphorilated using SAP 
(Shrimp Alkaline Phosphatase) enzyme (Promega). One microgram of the resulting recombinant plasmid was cotransfected with $0.5 \mu \mathrm{g}$ of the viral DNA from vSynVI-gal [27] in Tn5B cells $\left(10^{6}\right)$ using liposomes (as described above). Seven days after co-transfection, the cell supernatant was collected and used for recombinant virus isolation by serial dilution in 96-well plates [28]. The recombinant virus was amplified by infection of Tn5B $\left(1.5 \times 10^{7}\right.$ cells) with an MOI of 1 in $75 \mathrm{Cm}^{2}$ flasks (TPP).

\section{Putative recombinant protein crystals purification}

Wild type and recombinant viruses were used to infect 200 S. frugiperda larvae each as described above. After the death by infection, the cadavers were homogenized with the same volume of $\mathrm{ddH}_{2} \mathrm{O}(\mathrm{w} / \mathrm{v})$, filtered through gauzes and centrifuged at 7,000 $\times \mathrm{g}$ for $10 \mathrm{~min}$. The supernatant was discarded and the pellet was resuspended in the same volume of $5 \%$ Triton X-100 and centrifuged at $7,000 \times g$ for $10 \mathrm{~min}$. This procedure was repeated twice. The last pellet was resuspended in $0.5 \mathrm{M} \mathrm{NaCl}$, centrifuged once more as above, and resuspended with $\mathrm{ddH}_{2} \mathrm{O}$. All solutions contained a Protease Inhibitor Cocktail (Sigma - according to notes of use). The suspended solution was loaded on a discontinuous sucrose gradient (40-80\% of sucrose in Phosphate Buffered Saline [PBS], $137.0 \mathrm{mM} \mathrm{NaCl}, 2.7 \mathrm{mM} \mathrm{KCl}, 10.0 \mathrm{mM} \mathrm{Na} \mathrm{HPO}_{4}$, $2.0 \mathrm{mM} \mathrm{KH} \mathrm{PO}_{4}, \mathrm{pH} 7.4$ ) and centrifuged at 130,000 $x \mathrm{~g}$ for $3 \mathrm{~h}$. The band containing the putative crystals were removed from the gradient, five-fold diluted with $\mathrm{ddH}_{2} \mathrm{O}$, and centrifuged at 7,000 $\propto \mathrm{g}$ for $10 \mathrm{~min}$. Cadavers of vAcpolh-6xhis-infected larva were purified according to standard method for polyhedra purification [28]. The purified crystals were subjected to SDS-PAGE and ultrastructural analysis.

\section{Microscopy analysis}

A monolayer of Tn5B cells $\left(5.0 \times 10^{6}\right)$ was infected at an MOI of 5 with vAc-polh-GarMbFV-cp-6xhis and vAcpolh-6xhis. The infected cells were observed and photographed at $72 \mathrm{~h}$ p.i. in an Axiovert 100 inverted light microscope (Zeiss). For scanning electron microscopy (SEM), the purified putative crystals were dried in a critical point-dried (Balzers) and coated with gold in a Sputter Coater (Balzers) before being observed in a SEM Jeol JSM $840 \mathrm{~A}$ at $10 \mathrm{kV}$.

\section{Analysis of recombinant protein synthesis}

Tn5B cells $\left(5.0 \times 10^{6}\right)$ were infected $(10 \mathrm{pfu} / \mathrm{cell})$ with vSyn-GarMbFV-cp, vAc-polh-GarMbFV-cp-6xhis, vAcpolh-6xhis, and the wild-type AcMNPV. At $72 \mathrm{~h}$ p.i., the infected cells were collected and centrifuged at 10,000 $x$ $g$ for $2 \mathrm{~min}$. The resulting pellets were resuspended in PBS with an equal volume of $2 x$ protein loading buffer (0.25 M Tris-Cl, pH 6.8, 4\% SDS, 20\% glycerol, 10\% 2- mercaptoethanol, and $0.02 \%$ bromophenol blue). Proteins were heated $\left(100^{\circ} \mathrm{C}\right)$ for $5 \mathrm{~min}$ and analyzed by 12\% SDS-PAGE using the Mini Protean Tetra Cell aparatus (BioRad) following the manufacturer's instructions. For immunoblotting, samples were resolved by $12 \%$ SDS-PAGE and transferred onto a nitrocellulose membrane (Sigma) using the Trans-Blot ${ }^{\circ}$ SD - Semi Dry Transfer Cell (BioRad). The membrane was then blocked in $1 \times$ PBS Buffer (137 mM NaCl, $2.7 \mathrm{mM} \mathrm{KCl,} 10 \mathrm{mM}$ $\mathrm{Na}_{2} \mathrm{HPO}_{4}, 2 \mathrm{mM} \mathrm{KH} \mathrm{PO}_{4}, \mathrm{pH}$ 7.4) containing $3 \%$ skimmed milk powder for $16 \mathrm{~h}$ at $4^{\circ} \mathrm{C}$, washed three times with PBS tween (0.05\%) and probed with (i) mouse monoclonal anti-hexa-histidine (anti-6xHis) antibody (Sigma), (ii) rabbit anti-Polh antiserum [31], or (iii) antiPolh-GarMbFV-CP-6xHis (produced in this work) followed by incubation with the alkaline phosphataseconjugated anti-mouse/rat or anti-rabbit secondary antibodies (Sigma). Blots were developed using the NBT/BCIP (Sigma) substrate dissolved in alkaline phosphatase buffer $\left(\mathrm{NaCl} 100 \mathrm{mM}, \mathrm{MgCl}_{2} 5 \mathrm{mM}\right.$ e Tri- $\mathrm{HCl}$ $100 \mathrm{mM}-\mathrm{pH}$ 9.0).

\section{Immunization and antiserum production}

The purified recombinant crystals of Polh-GarMbFV$\mathrm{CP}-6 \mathrm{xH}$ is was dissolved for $1 \mathrm{~h}$ at $37^{\circ} \mathrm{C}$ in $0.1 \mathrm{M}$ of $\mathrm{Na}_{2} \mathrm{CO}_{3}$, neutralized with $0.1 \mathrm{M}$ of Tris- $\mathrm{HCl}(\mathrm{pH} 7.6)$ and centrifuged at $16,000 \times g$ for $30 \mathrm{~min}$. The protein concentration was estimated by SDS-PAGE, comparing different BSA concentrations with the query protein (data not shown). The solution was filter sterilized and used for quadriceps intramuscular injection firstly with Freund's complete adjuvant at 1:1 proportion, secondly with Freund's incomplete adjuvant at 1:1 proportion, and finally alone. Five Gnotobiotic Sprague-Dawley male rats strain CD, 8 weeks old with food and water ad libidum, were used in this immunization experiment. The project was reviewed by the Ethics Committee on Animal Use of the University of Brasília. The animals were immunized with 15 days intervals for each injection containing $500 \mu \mathrm{g}$ of the recombinant protein.

\section{Dot enzyme-linked immunosorbent assay (dot-ELISA)}

Garlic plants infected with Garlic Mite-borne Filamentous Virus (GarMbFV) showing typical symptoms on the leaves such as yellow mosaic, stripes, and distortion and a general plant growth reduction were collected in the garlic germplasm bank from Embrapa Vegetables (Brasilia-DF, Brazil). The garlic leafs were triturated in PBS using a proportion of $100 \mu \mathrm{l}$ of PBS per each $100 \mathrm{mg}$ of leaves. The samples were mixed with equal volumes of $2 \mathrm{X}$ protein loading buffer without stain and heated $\left(100^{\circ} \mathrm{C}\right)$ for 5 min. Purified antigen (Polh-GarMbFV-CP-6xHis), virusinfected, and non-infected leaf samples were manually dotted on a nitrocellulose membrane and probed against 
the crude rat anti-Polh-GarMbFV-CP-6xHis antiserum at 1:100, 1:500 and 1:1,000 (v/v) dilutions in 1X PBS plus $0.5 \%$ BSA $(\mathrm{w} / \mathrm{v})$ followed by incubation with the alkaline phosphatase-conjugated mouse secondary antibodies (Sigma) and NBT/BCIP substrate (Sigma) in alkaline phosphatase buffer. The positive and negative control plant extracts were confirmed by RT-PCR according to Fayad-André et al. (2011).

\section{Competing interests}

The authors declare that they have no competing interests.

\section{Authors' contributions}

Conceived and designed the experiments: DMPAA, BMR, ROR. Performed the experiments: DMPAA, JRR, MHOC, Analyzed the data: DMPAA, BMR, ROR. Contributed reagents/materials/analysis tools: BMR, ROR, ALB, AND. Wrote the paper: DMPAA, BMR, ROR. All author s read and approved the final manuscript.

\section{Acknowledgements}

We thank Embrapa Recursos Genéticos e Biotecnologia-CENARGEM for kindly providing the Spodoptera frugiperda larva; Dr. Miguel Alves-Júnior for constructing the vSyn-GarMbFV-cp recombinant virus; Dra. Fernanda Rausch Fernandes from Empraba Vegetables for providing garlic leaf extracts; Professor Dr. Fernando Lucas Melo for the critical reading of the manuscript and Fernanda Araújo Ferreira for kindly reviewing the English.

\section{Author details}

${ }^{1}$ Department of Cell Biology, Laboratory of Electron Microscopy, Institute of Biological Sciences, University of Brasília, Brasília, DF, Brazil. ²Embrapa Vegetables, Embrapa, Brasília, Brazil.

Received: 19 June 2013 Accepted: 14 August 2013

Published: 15 August 2013

\section{References}

1. Lot H, Chovelon V, Souche S, Delecolle B: Effects of onion yellow dwarf and leek yellow stripe viruses on symptomatology and yield loss of three French garlic cultivars. Plant Dis 1998, 82:5.

2. Conci VC, Canavelli A, Lunello P, Rienzo JD, Nome SF, Zumelzu G, Italia R: Yield losses associated with virus-infected garlic plants during five successive years. Plant Dis 2003, 87:5

3. Lunello P, Rienzo JD, Conci VC: Yield Loss in Garlic Caused by Leek yellow stripe virus Argentinean Isolate. Plant Dis 2007, 15:6

4. Torres AC, Fajardo TV, Dusi AN, Resende RO, Buso JA: Shoot tip culture and thermotherapy for recovering virus-free plants of garlic. Horticultura Brasileira 2000, 18:3.

5. Tsuneyoshi T, Sumi S: Differentiation among garlic viruses in mixed infections based on RT-PCR procedures and direct tissue blotting immunoassays. Phytopathology 1996, 86:7.

6. Tsuneyoshi T, Matsumi T, Natsuaki KT, Sumi S: Nucleotide sequence analysis of virus isolates indicates the presence of three potyvirus species in Allium plants. Arch Virol 1998, 143:97-113.

7. Takaichi M, Nagakubo T, Oeda K: Mixed virus infections of garlic determined by a multivalent polyclonal antiserum and virus effects on disease symptoms. Plant Dis 2001, 85:5

8. Fayad-André MS, Dusi AN, Resende RO: Spread of viruses in garlic fields cultivated under different agricultural production systems in Brazil. Trop Plant Pathol 2011, 36:3.

9. Huttinga $\mathrm{H}$ : Purification by molecular sievin of a leak virus related to onion yellow dwarf virus. Netherland J Plant Pathol 1975, 81:3.

10. Albrechtsen M, Heide M: Purification of plant viruses and virus coat proteins by high performance liquid chromatography. J Virol Methods 1990, 28:245-256.

11. Filho FACR, Lima JA, Ramos NF, Gonçalves MFB, Carvalho KF: Produção de anti-soro para o vírus do mosaico da abóbora mediante imunização oral de coelhos. Revista Ciência Agronômica 2005, 36:4

12. Alves-Junior M, Marraccini FM, Melo Filho PA, Dusi AN, Pio-Ribeiro G, Ribeiro BM: Recombinant expression of Garlic virus C (GARV-C) capsid protein in insect cells and its potential for the production of specific antibodies. Microbiol Res 2008, 163:354-361.

13. Jarvis DL, Bohlmeyer DA, Garcia A Jr: Enhancement of polyhedrin nuclear localization during baculovirus infection. J Virol 1992, 66:6903-6911.

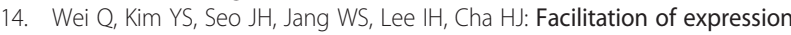
and purification of an antimicrobial peptide by fusion with baculoviral polyhedrin in Escherichia coli. Appl Environ Microbiol 2005, 71:5038-5043.

15. Seo JH, Yeo JS, Cha HJ: Baculoviral polyhedrin-Bacillus thuringiensis toxin fusion protein: a protein-based bio-insecticide expressed in Escherichia coli. Biotechnol Bioeng 2005, 92:166-172.

16. Roh JY, Choi JY, Kang JN, Wang Y, Shim HJ, Liu Q, Tao X, Xu HG, Hyun J, Woo SD, et al: Simple purification of a foreign protein using polyhedrin fusion in a baculovirus expression system. Biosci Biotechnol Biochem 2010, 74:5.

17. Lee KS, Sohn MR, Kim BY, Choo YM, Woo SD, Yoo SS, Je YH, Choi JY, Roh JY, Koo HN, Jin BR: Production of classical swine fever virus envelope glycoprotein E2 as recombinant polyhedra in baculovirus-infected silkworm larvae. Mol Biotechnol 2012, 50:211-220.

18. Bae SM, Kim HJ, Lee JB, Choi JB, Shin TY, Koo HN, Choi JY, Lee KS, Je YH, Jin $B R$, et al: Hyper-enhanced production of foreign recombinant protein by fusion with the partial polyhedrin of nucleopolyhedrovirus. PLOS One 2013, 8:e60835.

19. Conci V, Nome SF, Milne RG: Filamentous viruses of garlic in Argentina. Plant Dis 1992, 76:3.

20. van Dijk P: Carlavirus isolates from cultivated Allium species represent three viruses. Netherland I Plant Pathol 1993, 99:25.

21. Ji X, Sutton G, Evans G, Axford D, Owen R, Stuart Dl: How baculovirus polyhedra fit square pegs into round holes to robustly package viruses. EMBO J 2010, 29:505-514.

22. Molinari P, Crespo MI, Gravisaco MJ, Taboga O, Moron G: Baculovirus capsid display potentiates OVA cytotoxic and innate immune responses. PLoS One 2011, 6:e24108

23. Fajardo TVM, Nishijima M, Buso JA, Torres AC, Ávila AC, Resende RO: Garlic Viral Complex: Identification of Potyviruses and Carlavirus in Central Brazil. Fitopatologia Brasileira 2001, 26:8.

24. Mituti T, Marubayashi JM, Moura MF, Krause-Sakate R, Pavan MA: First Report of Shallot latent virus in Garlic in Brazil. Plant Dis 2011, 95:1.

25. Melo Filho PA, Nagata T, Dusi NA, Buso JA, Torres AC, Eiras M, Resende RO: Detection of three Allexivirus species infecting garlic in Brazil. Pesquisa Agropecuária Brasileira 2004, 39:5.

26. Granados RR, Guoxun L, Derksen ACG, Mckenna KA: A new insect cell line from Trichoplusia ni (BTI-Tn-5B1-4) susceptible to Trichoplusia ni single enveloped nuclearpolyhedrosis virus. J Invertebrate Pathol 1994, 64:6.

27. Wang XZ, Ooi BG, Miller LK: Baculovirus vectors for multiple gene expression and for occluded virus production. Gene 1991, 100:131-137.

28. O'Reilly D, Miller LK, Luckow VA: Baculovirus Expression Vectors: a laboratory manual. New York: Freeman and Company; 1992

29. Greene GL, Leppla NC, Dickerson WA: Velvetbean caterpillar: a rearing procedure and artificial medium. J Economical Entomol 1976, 69:2.

30. Sambrook J, Russel DW: Molecular Cloning: a laboratory manual. 3rd ed. edn. New York: Cold Spring Harbor; 2001

31. Ribeiro BM, Generino AP, Acacio CN, Kalapothakis E, Bao SN: Characterization of a new Autographa californica multiple nucleopolyhedrovirus (AcMNPV) polyhedra mutant. Virus Res 2009 140:1-7.

doi:10.1186/1743-422X-10-262

Cite this article as: Ardisson-Araújo et al:: A baculovirus-mediated strategy for full-length plant virus coat protein expression and purification. Virology Journal 2013 10:262. 